\title{
Keeping Stigma out of Administrative Law: An Explanation of Consistent Beliefs
}

Roberto Galbiati

Nuno Garoupa

ngaroup@gmu.edu

Follow this and additional works at: https://scholarship.law.tamu.edu/facscholar

Part of the Law Commons

\section{Recommended Citation}

Roberto Galbiati \& Nuno Garoupa, Keeping Stigma out of Administrative Law: An Explanation of Consistent Beliefs, 15 Sup. Ct. Econ. Rev. 273 (2007).

Available at: https://scholarship.law.tamu.edu/facscholar/519

This Article is brought to you for free and open access by Texas A\&M Law Scholarship. It has been accepted for inclusion in Faculty Scholarship by an authorized administrator of Texas A\&M Law Scholarship. For more information, please contact aretteen@law.tamu.edu. 


\title{
Keeping Stigma Out of Administrative Law: An Explanation of Consistent Beliefs
}

\author{
Roberto Galbiati* and Nuno Garoupa**
}

\begin{abstract}
We provide an interpretation based on consistent beliefs for the widely accepted observation that a criminal conviction generates more stigma than an administrative penalty. Implications for the criminalization of administrative noncompliance are discussed.
\end{abstract}

\section{IN TRODUCTION}

It is widely accepted that a criminal conviction generates more stigma for the convicted party than an administrative penalty. ${ }^{1}$ In this paper we provide an explanation of this observation based on consistent beliefs about the reliability of information concerning guilt transmitted by a conviction under administrative and criminal regimes. In particular, we show that the higher stigma associated with criminal convictions is justified on the grounds that a criminal conviction conveys more reliable information about guilt than an administrative one. Although a criminal conviction is less easily obtained due to a higher

* Department of Economics and Max Weber Program, European University Institute. Via delle Fontanelle 10, 50016 San Domenico (Fi) Italy. Email: roberto.galbiati @eui.eu.

* * Faculdade de Economia, Universidade Nova de Lisboa, Campus de Campolide, P-1099-032 Lisboa, Portugal. Phone: $+351-213801600$. Fax: $+351-213870933$. Email: ngaroupa@fe.unl.pt. The authors would like to thank Richard McAdams and two anonymous referees for helpful comments. Financial support by Nova Forum and FCT, POCTI/ECO/44146/2002 is gratefully acknowledged by Garoupa. The usual disclaimer applies.

' Ashworth calls them non-severe sanctions, including regulatory proceedings, administrative offences, or civil sanctions. See A. Ashworth, Principles of Criminal Law (Oxford, 2003). 
standard of proof and the need to consider a mental state, it is also more reliable because a higher standard of proof guarantees that fewer innocents are mistakenly convicted. Hence we argue that if the proportion of mistaken convictions is lower in a criminal than in an administrative regime, then it makes sense for society to extract more information concerning guilt (and therefore how individual preferences look like) from a criminal conviction, and to pay less attention to the application of administrative penalties. ${ }^{2}$

Generally speaking, there are two kinds of legal sanctions, the kind that are accompanied by stigma and the kind that are not. Many commentators assume that the difference between the two is entirely due to the substance of the prohibition, e.g., speeding (no stigma) versus murder (stigma). Our point is that procedure (that is, the standard of proof) makes an important contribution towards whether or not there is stigma. An immediate consequence of this observation is that the government has some control over whether its penalties cause stigma. ${ }^{3}$

We do not pursue here the discussion on stigma as an efficient deterrent, ${ }^{4}$ nor do we justify the optimal combination of criminal and administrative law. ${ }^{5}$ Our point is simply to state that the fact that criminal convictions are more stigmatizing than administrative penalties is easily understood as the outcome of consistent beliefs concerning guilt, and this rationale has important implications for legal policies. ${ }^{6}$

Our explanation has consequences for the debate over the reform

${ }^{2}$ Our argument is independent of the moral neutrality of regulatory or administrative offenses. Coffee and Green present opposing views. J. Coffee, Reflections on the Disappearing Tort/Crime Distinction in American Law, 71 Buffalo Univ L Rev 193 (1991). S.P. Green, Why It is a Crime to Tear the Tag Off a Mattress: Overcriminalization and the Moral Content of Regulatory Offenses, 46(4) Emory L I 1533-1615 (1997). Green also points out the ambiguity given to white-collar wrongdoings. S.P. Green, Moral Ambiguity in White Collar Criminal Law, 18 Notre Dame J L, Ethics, \& Pub Policy 501-519 (2004).

${ }^{3}$ The economic theory of regulation has not addressed the problem because it has not paid enough attention to institutional details, hence usually referring to sanctions in a broad sense, not distinguishing regulatory or administrative penalties from criminal sanctions; see J.J. Laffont and J. Tirole, $A$ Theory of Incentives in Procurement and Regulation (Cambridge, 1993). For an exception, see P. Fenn and C. Veljanovski, A Positive Economic Theory of Regulatory Enforcement, 98 Econ J 1055-77 (1988).

${ }^{4}$ See E. Rasmusen, Stigma and Self-Filling Expectations of Criminality, $39 \mathrm{~J} \mathrm{~L} \mathrm{\&}$ Econ 519-44 (1996); D.L. Wong, Stigma: A More Efficient Alternative to Fines in Deterring Corporate Misconduct, 3 Cal Crim L Rev Article 3 (2000); K. Furuya, A SocioEconomic Model of Stigma and Related Social Problems, $48 \mathrm{~J}$ Econ Beh \& Org 281-90 (2002); P. Funk, On the Effective Use of Stigma as a Crime-Deterrent, 48(4) Eur Econ Rev 715-25 (2004).

${ }^{5}$ N. Garoupa F. Gomez-Pomar, Punish Once or Punish Twice: A Theory of the Use of Criminal Sanctions in Addition to Regulatory Penalties, 6(2) Amer L \& Econ Rev 410-33 (2004).

${ }^{6}$ Obviously, our results are reinforced by the fact that criminal proceedings are more expensive than administrative proceedings. 
of administrative law in the sense that the suggestions offered by several authors will affect the differences in the re-liability of convictions in conveying valuable information. In particular we argue that changes in the standard of proof; ${ }^{7}$ the replacement of the current so-called compliance strategy pursued by regulatory agencies by a more sanctioningoriented strategy typical of prosecution; ${ }^{8}$ the enforcement of identical guidelines on police and prosecution services as well as on regulatory agencies; $^{9}$ or the empowerment of criminal courts in the area of administrative law $^{10}$ will dilute beliefs. Our reasoning has further important implications about the publicity of convictions. Namely, as the level of stigmatization depends on both the reliability of information about guilt and from publicity, policies aiming at increasing the level of publicity for administrative offences (e.g., tax evasion, traffic accidents, corporate crimes) without appropriate changes in the procedure would certainly raise stigma, but create some other important problems. In particular, such policies might weaken the reliability of the information provided by convictions and might create inefficient and unfair stigma.

The reduction of the differentials between beliefs is positive if one takes the view that the stigma differential should not exist, but it will be problematic if this stigma differential is part of efficient deterrence. ${ }^{11}$ Our rationale also applies to the fact that the payment of damages in tort law does not create much stigma, but that has not generated the same criticism as administrative law. ${ }^{12}$

' For example, Ashworth points out that "when instances of significant wrongdoing are moved from the criminal to the civil law in order to avoid the criminal protections, serious questions of propriety are raised." A. Ashworth, Principles of Criminal Law (Oxford, 2003).

${ }^{8}$ For a theoretical approach, see P. Fenn and C. Veljanovski, A Positive Economic Theory of Regulatory Enforcement, 98 Econ J 1055-77 (1988). For the argument that such a trend is already observable in practice, see R. Baldwin, The New Punitive Reg. ulation, 67 Mod L Rev 351-83 (2004).

${ }^{9}$ In general, see A. Ashworth, The Criminal Process: an Evaluative Study |Oxford, 1988); in detail, see G. Richardson, Strict Liability for Regulatory Crime: The Empirical Research, 1987 Crim L Rev 295-99.

${ }^{10}$ For example, where there are separate proceedings for administrative or regulatory offenses, the European Court of Human Rights requires it be open to defendants to have the case heard in a criminal court if desired.

${ }^{11}$ See J.M. Karpoff and J.R. Lott, The Reputational Penalty Firms Bear from Committing Criminal Fraud, 36 J L \& Econ 757-802 (1993) and N. Garoupa, 21 (6) Managerial \& Decision Econ 243 -252 (2000), on corporate criminal liability. Contrast with Wong, 3 Cal Crim L Rev 3 (cited in note 4). On the efficient nature of shaming penalties, see D. Kahan, What do Alternative Sanctions Mean?, 63 U Chi L Rev 591 (1996).

${ }^{12}$ With the possible exception of the debate over punitive damages. See G. Heriot, An Essay on the Civil-Criminal Distinction with Special Reference to Punitive Damages, 7 J Contemp L 43 (1996), K. Mann, Punitive Civil Sanctions: The Middleground Between Criminal and Civil Law, 101 Yale L J 1795 (1992), and A.M. Polinsky and S. Shavell, Punitive Damages: An Economic Analysis, 11 Harv L Rev $869-962$ (1998). 
Finally, a general implication for the normative theory of law enforcement can be singled out from our reasoning. The mathematical condition we derive to impose consistency between criminal and administrative convictions and beliefs shows that maximal fines are hardly appropriate. The rationale is that maximal criminal fines would increase deterrence by far and hence the proportion of legal mistakes would also increase /since we would have more innocents and fewer guilty in relative terms). This result contrasts with previous literature..$^{13}$

This paper is structured as follows: in section two, we introduce the model; in section three, we discuss the implications for administrative law; and concluding remarks are presented in section four.

\section{The Model}

\section{A. Basic Setup}

We use the basic framework of Polinsky and Shavell to study under which conditions criminal law is a more reliable instrument than administrative law in order to issue information concerning guilt and hence produce stigma. ${ }^{14}$ The following standard notation is used: $b$ is the illegal gain from committing an offense (private information); $f$ is the legal sanction (monetary/non-monetary); $s$ is the cost of stigma (in general, an extralegal sanction); $p$ is the apprehension and conviction probability for the guilty; and $q$ is the apprehension and conviction probability for the innocent. Consequently, innocents are wrongly convicted with probability and criminals are wrongly acquitted with probability $1-p$.

A potential wrongdoer will commit an unlawful act if $b-p(f+s)$ $\geq-q(f+s)$ or analogously, if $b>(p-q)(f+s)$. The population is normalized to one and the illegal gain is distributed across the population according to a probability density function $g(b)$ and a cumulative density function $G(b)$ with support in the interval $[0, \infty)$. The number of criminals is given by $1-G((p-q)(f+s))$ and the number of honest individuals is $G((p-q)(f+s))$.

The reliability of conviction in conveying information about guilt is given by the following expression (total number of convicted guilty divided by total number of convictions as in Bayesian inference):

$$
\mu(p, q, f+s)=\frac{p(1-G((p-q)(f+s))}{p(1-G((p-q)(f+s))+q G((p-q)(f+s))}
$$

${ }^{13}$ A.M. Polinsky and S. Shavell, The Economic Theory of Public Enforcement of Law, 38 J Econ Lit 45-76 (2000).

${ }^{14}$ Id. 


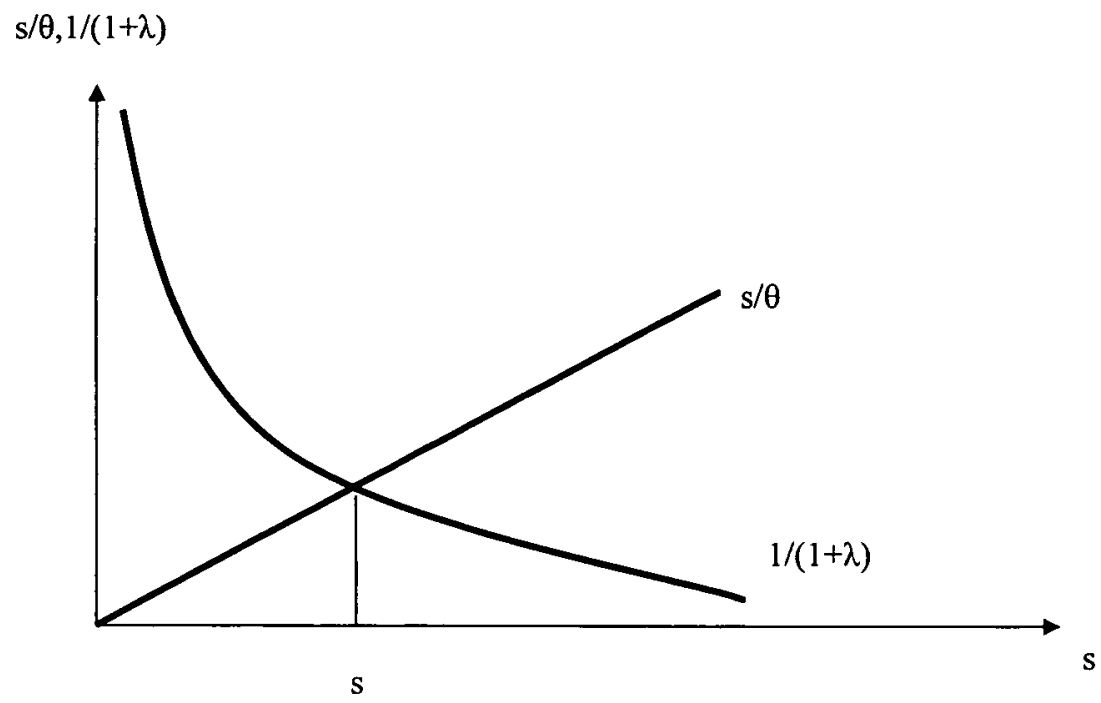

Figure 1.

The reliability of conviction expressed by (1) can be rearranged as:

$$
\begin{aligned}
\mu(p, q, f+s) & =\frac{1}{1+\lambda(p, q, f+s)} \\
\lambda(p, q, f+s) & =\frac{q G((p-q)(f+s))}{p(1-G((p-q)(f+s))}
\end{aligned}
$$

Notice that the reliability of conviction is strictly decreasing in the extralegal sanction $s$ /due to the fact that it increases deterrence, and therefore the number of wrongly convicted individuals increases in relation to the number of correctly convicted criminals).

In this setup, the extralegal sanction (stigma) is determined by the reliability of conviction and the publicity it gets from the government in the following way:

$$
s=\theta \mu(p, q, f+s)=\frac{\theta}{1+\lambda(p, q, f+s)}
$$

where $\theta$ can be seen as the probability that individuals will be aware of convictions. Figure 1 illustrates the stigma obtained by a conviction given all other parameters of the model.

\section{B. Criminal Versus Administrative Law}

Let us now consider criminal and administrative offenses. The subscript $\mathrm{C}$ designates criminal law and A designates administrative law. 
From here on, we denote by simplicity $G\left(\left(p_{i}-q_{i}\right)\left(\left(f_{i}-s_{i}\right)\right)=G_{i}\right.$. We rely upon the following assumptions:
(i) $f_{C}>f_{A}$;
(ii) $q_{C}>q_{A}$ i
(iii) $p_{C}>p_{A}$;
(iv) $p_{C}>q_{C}$;
(v) $p_{A}>q_{A}$;
(vi) $q_{A} / p_{A}=q_{C} / p_{C}$;
(vii) $\theta_{C}>\theta_{A}$.

Assumption (i) is consistent with the observation that a conviction in criminal law is more severe than in administrative law. Assumptions (ii) and (iii) imply that convictions are easier to both the innocent and the guilty in administrative law due to the lower standard of proof ${ }^{15}$. Assumptions (iv) and (v) state that the probability of convicting the guilty is higher than that for the innocent for both criminal sanctions and administrative penalties. Assumption (vi) indicates that the probability of a wrong conviction is the same under both regimes for a given probability of a correct conviction. That is, if the probability of conviction of an offender were the same under both regimes then so it would the probability of conviction of an innocent (hence the lower standard of proof in administrative law hurts offenders and innocents in the same way). Finally, assumption (vii) captures the idea that criminal convictions get more publicity than administrative ones.

The observation that criminal law is associated with more stigma than administrative law, $s_{C}>s_{A}$ implies that:

$$
\frac{\theta_{C}}{1+\lambda_{C}(p, q, f+s)}>\frac{\theta_{A}}{1+\lambda_{A}(p, q, f+s)}
$$

Higher stigma for criminal convictions can be explained by two facts. The first reason has to do with more publicity of convictions. The second explanation relates to the information concerning guilt transmitted by a conviction ${ }^{16}$. Conviction under a regime of criminal law transmits information about guilt more reliably than in a regime of administrative law if $\lambda_{C}>\lambda_{A}$, that is if:

${ }^{15}$ It is worth noting that not only different standard of proofs but also a mens rea requirement makes it much more difficult to observe a criminal conviction than an administrative one. Indeed a mental state such as intent, knowledge, or recklessness is usually required for a criminal conviction. By contrast, administrative laws are usually enforced on the basis of strict liability and consequently are much easier. We thank an anonymous referee for having suggested us this point.

${ }^{16}$ There might be an intrinsic relationship between publicity and information concerning guilt. It seems plausible that the greater publicity for criminal convictions could arise because of the greater reliability of the underlying information. Nevertheless that is affected by the way authorities deal with criminal convictions and depends on the structure of the market for publicity which we do not discuss here. 


$$
\frac{q_{C} G_{C}}{p_{C}\left(1-G_{C}\right)}<\frac{q_{A} G_{A}}{p_{A}\left(1-G_{A}\right)}
$$

Given our assumption (vi), the above condition is reduced to $G_{C}>$ $G_{A}$. A conviction under a regime of criminal law is more reliable if and only if criminal law is less effective as a deterrent ${ }^{17}$. From (5), the reason is quite intuitive: criminal law is more reliable because the proportion of innocents (hence of convicted innocents) is lower and the proportion of criminals (hence of convicted criminals) is higher than under administrative law.

A conviction under criminal law is a more reliable means for conveying information about guilt when:

$$
\left(p_{C}-q_{C}\right)\left(f_{C}+s_{C}\right)<\left(p_{A}-q_{A}\right)\left(f_{A}+s_{A}\right)
$$

The necessary condition to satisfy $(6)$ is that $\left(p_{C}-q_{C}\right)$ is much lower than $\left(p_{A}-q_{A}\right)$ which is consistent with our assumptions. ${ }^{18}$

Remark 1: Given the higher standard of proof of criminal law, a criminal conviction conveys information about guilt more reliably (and consistently implies higher stigma) whenever $\left.\left(f_{C}+s_{C}\right)>\mid f_{A}+s_{A}\right)>\left(p_{C}\right.$ $\left.-q_{C}\right) /\left(p_{A}-q_{A}\right)\left(f_{C}+s_{C}\right)$.

The remark above has some normative implications for limiting the magnitude of criminal sanctions in contrast with the usual law enforcement literature. ${ }^{19}$ For a given probability of convicting the guilty and error of convicting the innocent, the overall criminal (legal and extralegal) sanction should not exceed the administrative (legal and extralegal) penalty for more than a certain amount. In particular when the stigma associated with criminal sanctions is particularly higher than that associated with administrative penalties; the legal criminal sanction (e.g. a fine) could be close to the legal administrative penalty ${ }^{20}$ Certainly, maximal fines are hardly consistent with our setup.

17 Notice that in our framework the prosecutor behaviour is considered as exogenous. This implies that there is no reaction of the prosecutor to the lower reliability of convictions occurring when maximal sanctions deter almost all potential criminals, for example, there is no increase in the burden of proof needed to prosecute as a reaction to higher sanctions. Hence, whatever is the reliability of convictions the probabilities of conviction are given.

${ }^{18}$ Indeed notice that $p_{C}\left(1-q_{C} / p_{C}\right)<p_{A}\left(1-q_{A} / p_{A}\right)$ is equivalent to $p_{C}<p_{A}$ by assumption (vi).

${ }^{19}$ Namely, the Beckerian maximal fine. See G.S. Becker, Crime and Punishment: An Economic Approach, 76 J Pol Econ 169-217 (1968); Polinsky and Shavell, 11 Harv L Rev at 869-962 (cited in note 12).

${ }^{20}$ There is some economic literature on discounting extra-legal sanctions, see R. Cooter and A. Porat, Should Courts Deduct Nonlegal Sanctions from Damages! 30 J Legal Stud 401-22 (2001). 
Figures two and three present the two possible cases where $s_{C}>s_{A}$ and consistent with our explanations, figure 2 refers to a situation where criminal law provides more reliable information concerning guilt (condition (6) is satisfied), whereas figure 3 shows the situation where although criminal law does not provide more reliable informa-

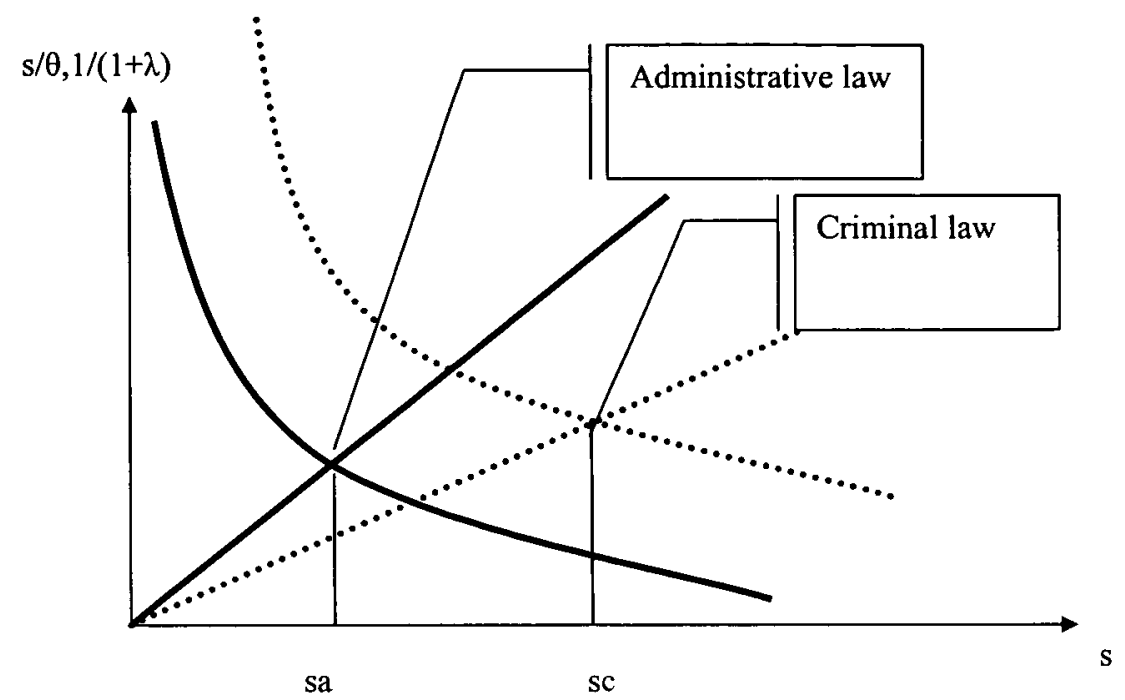

Figure 2.

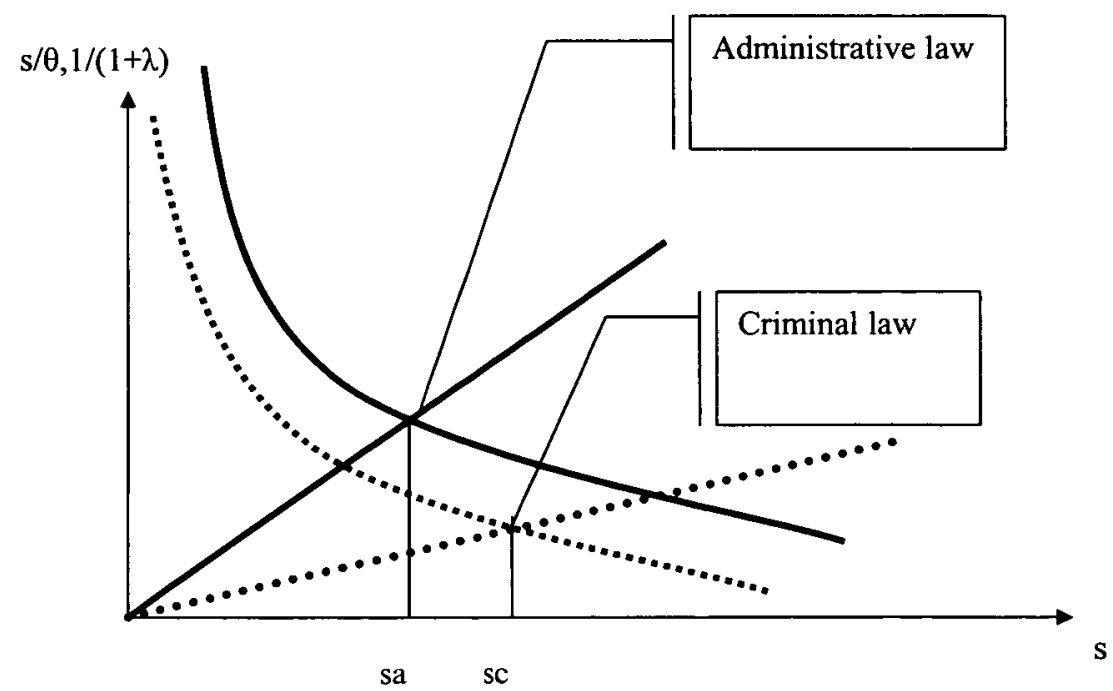

Figure 3. 
tion (condition (6) is not satisfied) the fact that it gets more publicity produces the result in terms of stigma.

\section{IMPLICATIONS FOR REFORM OF ADMINISTRATIVE LAW}

Our model suggests that a criminal conviction conveys information about guilt in a more reliable way than an administrative conviction. Therefore, more stigma for criminal sanctions is justified than for administrative penalties. The growth of regulatory offences and the range of administrative law in modern societies have raised several objections by legal commentators. Several authors have called for the reform of administrative law in the sense of criminalizing regulatory offences, or at least reduce the striking differences between criminal and administrative convictions.

One possibility is to ask regulatory agencies to provide publicity of convictions inasmuch as criminal convictions get more attention. The objective of this measure would be to increase stigma for corporations, tax evaders or individuals who cause traffic accidents. In terms of our model, let the government increase the publicity for administrative convictions from $\theta_{A}$ to $\theta_{C}$. The consequences of this policy will depend on which situation we are in terms of figures two and three. Figures 4 and 5 provide a graphical analysis of the following remarks:

Remark 2: Suppose $G_{C}<G_{A}$. When the government increases $\theta$ from $\theta_{A}$ to $\theta_{C}$, the stigma generated by a conviction under administrative law increases but does not achieve $s_{C}$. At the same time, the degree of reliability of the information provided by an administrative conviction decreases.

Remark 3: Suppose $G_{A}<G_{C}$. When the government increases $\theta$ from $\theta_{A}$ to $\theta_{C}$, the stigma generated by a conviction under administrative law increases and is above $s_{C}$. At the same time, the degree of reliability of the information provided by an administrative conviction decreases.

The provision of criminal publicity for convictions by regulatory agencies would certainly raise stigma, but creating an important problem in our view. It weakens the reliability of the information provided by such conviction (an apparently strange result given that stigma increases, but not so if we take into consideration that such increase is due to the publicity). Also, we should not disregard the fact that given the higher likelihood of mistaken convictions for the innocents, this policy might create inefficient and unfair stigma. 


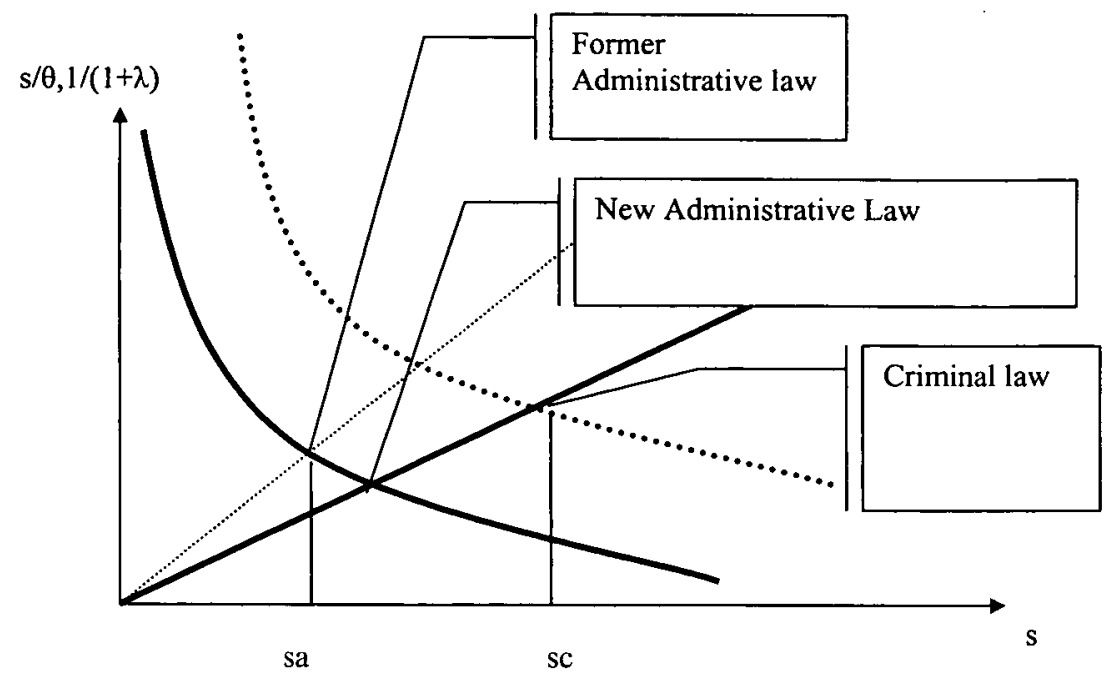

Figure 4.

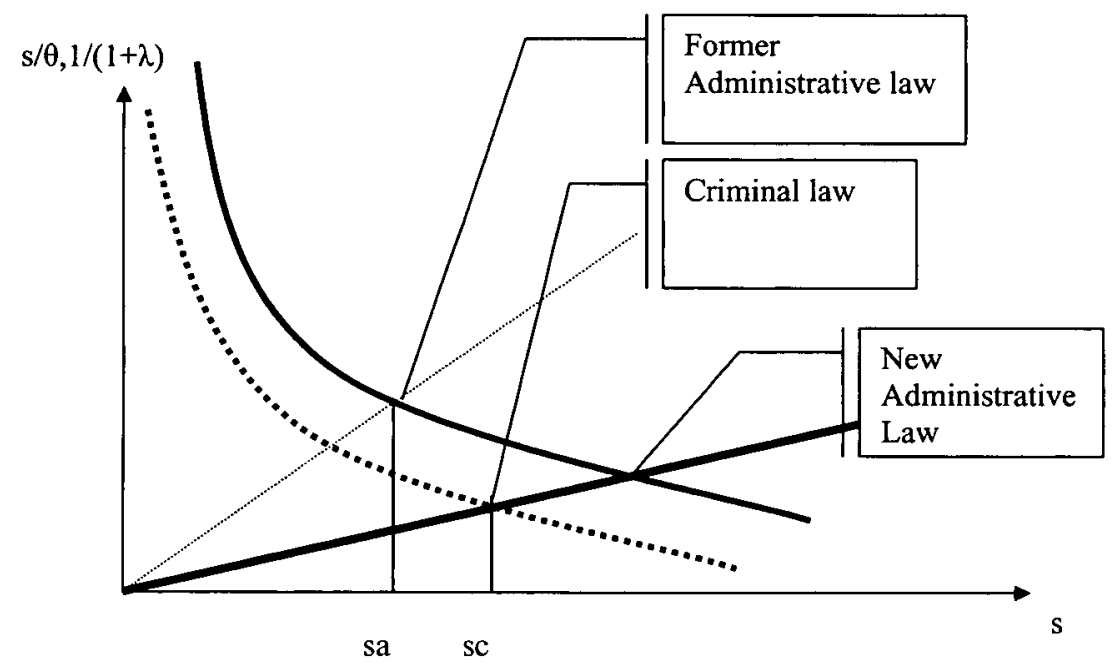

Figure 5.

\section{CONCLUSIONS}

This paper provides an alternative explanation to the observation that criminal convictions are more stigmatized than administrative ones. The literature has often emphasized that stigmatization depends on the gravity of the act causing the conviction. We suggest that an al- 
ternative explanation may rest in the reliability of information about guilt, and so about preferences, of those convicted. ${ }^{21}$

We derive several theoretical implications. In particular we show that a criminal conviction conveys information about guilt in a more reliable way than an administrative conviction. Therefore, more stigma attached to criminal sanctions than to administrative penalties is justified. We also derive a normative implication for the theory of optimal law enforcement. Indeed we show that imposing maximal sanctions in criminal proceedings is not consistent with reliability in conveying information because it would generate too many incorrect criminal convictions / since a much large proportion of potential criminals would be deterred) and therefore reduce the ability to extract information concerning guilt from a criminal record. On the policy ground our reasoning has some implications for the debate about the reduction in differences between criminal and administrative convictions that have been called for by several authors. We show that higher publicity in the administrative law may be inconsistent with beliefs and lead to inefficient or unfair stigma. Proposals have been made in the direction of avoiding decriminalization of regulatory offences, including the discretionary power of regulatory agencies when compared to the police or prosecution services. In order to reduce these differences, the enforcement of identical guidelines and accountability rules on police and prosecution services as well as on regulatory agencies has been proposed. All these measures will reduce the discrepancies between administrative and criminal proceedings, which naturally will reduce the signalling characterization of criminal convictions.

${ }^{21}$ Our argument relies on different standards of proof and probability of convicting the innocents (and acquitting the guilty) of administrative and criminal law. A related argument relies on mens rea. Indeed, stigmatization may depend on the mental state of the wrongdoer (namely the intent of the wrongdoer to harm) as the explicit intent to harm would be a stronger signal of individual preferences than the mere causation of the harm. In this case, strict administrative liability is a very weak signal of the wrongdoer's intent to harm (and so of his/her preferences), whereas a criminal conviction requiring for mens rea is a stronger signal of the individual's preferences. The legal policy implications of such an argument would be very similar to those of our reasoning. 
